\title{
DURATION OF UNEMPLOYMENT: GEOGRAPHIC MOBILITY AND SELECTIVITY BIAS
}

\author{
Ernest Preston Goss, Chris Paul, and Al Wilhite*
}

\begin{abstract}
Past researchers, examining the duration of joblessness, have failed to include a variable to account for the unemployed's migration decision. By employing a simultaneous structure with a censored dependent variable and an endogenous binary migration variable, the present study demonstrates that single stage models, which do not control for migration, produce selectivity bias in the estimated duration equation. The empirical model used in this study provides estimated coefficients that differ significantly from those of single stage models. For example, most past studies conclude that nonwhites suffer longer periods of unemployment than whites. The findings from the present study indicate that, after controlling for geographic mobility, there is no statistical difference in unemployment duration between whites and nonwhites.
\end{abstract}

\section{INTRODUCTION}

Empirical research on unemployment has measured wide variation in the amount of time unemployed workers take to find jobs. Identification of the causes of this variation occupies a position of central importance in the development and implementation of govermmental labor market and welfare policies. Many studies, for example, have focused on the impact of unemployment insurance and other government transfer payments on the length of job search (Feldstein 1975; Marston 1975; Ehrenberg and Oaxaca 1976). Others have addressed the role of individual worker characteristics such as age, education, health, and marital status to explain observed differences in search time (Nickell 1979; Kooreman and Ridder 1982; Folmer and Van Dijk 1985).

Job search theory, in general, assumes rational jobseekers attempting to maximize income, who search until a job offer is obtained that is greater than or equal to the worker's reservation wage. Furthermore, search theory assumes that the unemployed's reservation wage is a decreasing function of search time as the worker receives randomly distributed wage offers. Previous research has demonstrated that the reservation wage, and consequently search duration, is a function of labor market conditions and the unemployed's human capital endowments. Likewise, past research has usually assumed that the jobseeker contacts a fixed number of firms with vacancies per time period (Mortensen 1970). Contrary to this assumption, Seater (1979) found that a substantial increase in search inten-

*Jack MacAllister Chair in Regional Economics, Creighton University; Professor and Chair of Economics, University of Alabama, Huntsville; and Professor of Economics, University of Alabama, Huntsville, respectively. 
sity, via searching a larger area, led to a smaller increase in vacancy contacts. ${ }^{1}$ On the other hand, Schwartz (1976) concluded that searching a larger geographic area increases the number of job contacts and thereby reduces the length of search.

While several previous studies (David 1974; Goss and Schoening 1985; Goss 1988; Harkman 1989; and Goss and Paul 1990) have noted the geographical dimension of job search, most research studies have either ignored the geographic dimension of the job search process or assumed a simplistic link between area searched and search duration. Extending past research studies, which integrate a geographic dimension to the search process, the current study hypothesizes that job searchers allocate their search efforts on two margins. An intensive margin results in greater effort in searching the local labor market, while an extensive margin results in expanding the area of search. Assuming an individual maximizes his/her probability of locating an acceptable job offer, economic theory dictates that the individual searcher equate the relevant margins. However, economic theory generates indeterminate conclusions regarding which alternative possesses the higher marginal retum. Indeed, this is an empirical question with past applied research focusing almost exclusively on the intensive margin and ignoring the extensive margin or geographic dimension of the search process (Holzer 1987).

In terms of the extensive margin, models developed by Schwartz (1976) and Seater (1979) provide a theoretical connection between search duration and migration behavior or the radius of the search area. In his model, Schwartz assumes each worker faces a trade-off between the radius over which he or she searches for a job and the time it takes to find an acceptable wage offer. By expanding the search radius, a worker reduces search time. Conversely, the worker increases time spent searching for an acceptable job by reducing search radius. This relationship follows directly from the assumption that increasing the radius of search increases the number of available jobs within an occupation for a given reservation wage. Thus, if migration is viewed as a proxy for the radius of job search, Schwartz's model hypothesizes a negative relationship between migration and the duration of job search.

Altematively, Seater proposes a positive relationship between the search area size and the duration of joblessness. He hypothesizes that, due to travel time restrictions, it is more effective to search a small area intensively than a larger area less intensively. By assuming search is done in-person with the searcher visiting one firm and retuming home before continuing the search, he concludes that expanding the radius of search increases the time required to search the area proportionately more than the probability of finding an acceptable job. ${ }^{2}$ However, Seater offers no empirical support for his theoretical conclusions.

Both the Schwartz and Seater models assume that for a given reservation wage, the duration of unemployment (D) is a function of the radius of search (R), 
the worker's age (A), the worker's level of education (E), and the number of job vacancies $(\mathrm{V})$, which is also a function of $(\mathrm{R})$. It is further assumed that both the radius of search and the number of job vacancies are a function of a vector, $K$, representing labor market conditions confronting the unemployed worker and the worker's human capital endowments and life cycle characteristics. Schwartz's theoretical model is presented in Equation (1). ${ }^{3}$

$$
D=D[R(K), A, E, V(R, K)]
$$

Differentiating search time with respect to the radius of search produces Equation (2). The a priori signs of each term are inserted in parentheses below Equation (2).

$$
\partial \mathrm{D} / \partial \mathrm{R}=(\partial \mathrm{D} / \partial \mathrm{R})+(\partial \mathrm{D} / \partial \mathrm{V})(\partial \mathrm{V} / \partial \mathrm{R})
$$
$(+)$
$(-)$
$(+)$

In Equation (2), the first term ( $\partial \mathrm{D} / \partial \mathrm{R})$ is expected to possess a positive sign since searching a larger area will require a longer search time, ceteris paribus. On the other hand, the expected sign for $(\partial \mathrm{D} / \partial \mathrm{V})(\partial \mathrm{V} / \partial \mathrm{R})$ is negative since an increase in job vacancies will reduce the length of job search $[(\partial \mathrm{D} / \partial \mathrm{V})<0)]$, and increasing the radius of search increases the number of job vacancies $[(\partial V / \partial R)>$ 0].

According to the Seater model, the magnitude of the first term in Equation (2) dominates resulting in a net positive impact. Conversely, in the Schwartz model, the magnitude of the second term dominates, yielding an overall negative impact. Both models specify an explicit causal link between the radius of search and the duration of unemployment. Accordingly, duration models that do not include a variable to account for size of the geographic area searched misspecify the regression equation.

In the subsequent analysis, it is assumed that workers who search outside the local labor market have a larger search radius than those who search within the local labor market. Whether the worker searches outside the local labor market is proxied by ex post migration behavior. Clearly, with an unlimited time horizon, and $\mathbf{M}^{*}$ representing the probability of migration, each unemployed worker can:

1. Search in the local labor market only $\left(M^{*}=0\right)$.

2. Search in the local and distant labor markets $\left(0 \leq M^{*} \leq 1\right)$.

3. Search only in distant labor markets $\left(M^{*}=1\right)$. 
Though $\mathbf{M}^{*}$ is not observed, the actual ex post migration decision is. However, the use of a binary variable, equal to zero for nonmovers and one for movers, as an independent variable in the estimation of Equation (1) produces specification problems that preclude its use without a correction methodology. The appropriate correction methodology is discussed in the next section.

\section{MIGRATION, DURATION OF UNEMPLOYMENT, AND SELECTIVITY BIAS: A MIXED PROBIT APPROACH}

As argued in the previous section, geographic mobility enlarges the size of the search space and the observed number of job openings. Surprisingly, most published empirical studies examining the duration of unemployment do not control for geographic mobility. ${ }^{4}$ Since the omission of a relevant variable in the estimation of the duration of unemployment results in heterogenous error terms, models that do not control for geographic mobility produce biased estimates of the coefficients for the included variables. ${ }^{5}$ Heterogeneity refers to differences remaining in distributions after controlling for the effect of observed variables. Heterogeneity arises because migrants have different distributions of the dependent variable than nonmigrants, ceteris paribus.

According to Lancaster (1979), if geographic mobility affects unemployment duration and is correlated with explanatory variables included in the duration model, the estimated regression coefficients in the duration equation will be biased. Intuitively, if the migration variable is omitted as an independent variable, its impact will be partially reflected in the estimated coefficients of other variables as they inadvertently act as a surrogate for mobility.

However, the addition of a binary migration variable as an independent variable in the duration equation creates selectivity bias. The bias arises from selfselection since the distribution of unemployment spells is heterogenous across the two groups, migrants and nonmigrants. Formally, if the error term from the migration equation is correlated with the error term of the duration equation, loglikelihood estimates of the latter equation yield inconsistent estimates. The first step is to test for the existence of self-selection bias and then to eliminate its impact, if present. Procedures for this correction were developed by Heckman (1979) and Barnow et al. (1981).

First, according to Barnow et al., a decision equation is defined as:

$$
M_{i}^{*}=f\left(Z_{i}, E_{i}, e_{i}\right)
$$


where $\mathrm{Z}_{\mathrm{i}}$ is a vector of personal, family, and human capital variables, $\mathrm{E}_{\mathrm{i}}$ is a vector of economic and job-related factors describing the area, and $\mathrm{e}_{\mathrm{i}}$ is the error term reflecting unobserved random factors. The decision variable $\mathbf{M}_{i}^{*}$ is a measure of the ith worker's radius of search or propensity to move. However, $\mathrm{M}_{i}^{*}$ is not observed. $\mathrm{M}_{\mathrm{i}}$ is used as a proxy measure where:

$$
M_{i}=\left\{\begin{array}{l}
1 \text { if and only if migrant } \\
0 \text { if and only if nonmigrant }
\end{array}\right.
$$

Barnow's correction procedure requires the estimation of Equation (3) in the first stage using binary probit regression, and $\lambda$, as defined in Equations (5) and (6), is retained and inserted in the estimation of the unemployment duration equation.

$$
\begin{aligned}
& \lambda_{\mathrm{i}}=-\mathrm{f}\left(\mathrm{y}_{\mathrm{i}}\right) / \mathrm{F}\left(\mathrm{y}_{\mathrm{i}}\right) \quad\left(\text { where } \mathrm{M}_{\mathrm{i}}=1\right) \\
& \lambda_{\mathrm{i}}=-\mathrm{f}\left(\mathrm{y}_{\mathrm{i}}\right) /\left[1-\mathrm{F}\left(\mathrm{y}_{\mathrm{i}}\right)\right] \quad\left(\text { where } \mathrm{M}_{\mathrm{i}}=0\right)
\end{aligned}
$$

This procedure corrects for selectivity bias where $\mathrm{f}\left(\mathrm{y}_{\mathrm{i}}\right)$ is the density function and $F\left(y_{i}\right)$ is the cumulative distribution of a standard normal random variable. This two-stage, or simultaneous approach, allows one to determine the presence of selectivity bias by testing the null hypothesis for $\lambda$. Furthermore, it allows one to determine the impact of migration on the duration of joblessness by adding the migration indicator variable, $\mathbf{M}_{i}$, as a regressor. This method has been found to produce consistent estimated coefficients (Bamow, Cain, and Goldberger 1981; Greene 1985, 185).

Data limitations precipitate another econometric problem in the estimation of the duration equation. At the end of the sample period, some workers are still unemployed. Thus, the duration variable or dependent variable is right censored. Ignoring censoring leads to upward asymptotic bias in the estimated hazard rate or an underestimate of the completed spell of unemployment (Lancaster 1979). Censored data is not unusual in economic data, and techniques have been developed to calculate consistent estimates. Here the bias issue is addressed by including a censoring indicator in the likelihood function. Specifically, assuming a Weibull survival distribution, the likelihood function of the duration equation can be expressed as:

$$
L=\Pi_{i}\left(\sigma^{-1} f\left(w_{i}\right)\right)^{\delta i} F\left(w_{i}\right)^{1-\delta i}
$$

where $f(w)=\exp \left[\left(\log t-\beta^{\prime} x_{j}\right) / \sigma-e^{\left(\log t-\beta^{\prime} x j\right) / \sigma}\right]$ and $\delta$ is the right censoring indicator. 
In addition to allowing for $M$ and $\lambda$ as regressors, Equation (7) controls for heterogeneity among the unemployed in regard to human capital endowments, life cycle factors, labor market parameters, and right censoring of the dependent variable. To summarize the empirical estimation procedure, the migration equation is first estimated using binary probit regression and $\lambda$ and the binary migration indicator variable are retained and inserted in the estimation of the log-likelihood estimation of the duration equation. The next section discusses the empirical specifications of the migration and duration equations

\section{The Model}

Given the proposition that the same factors affecting migration also affect the length of joblessness, both the probit estimates of the migration equation and the log-likelihood estimation of the duration equation contain the same control variables. ${ }^{6}$ Equations (8) and (9) represent empirical specifications of the theoretical migration and unemployment duration equations, respectively. By including $\mathbf{M}$ and $\lambda$ in the second stage, Equation (9) is econometrically identified. The definition of each variable is presented in Table 1.

$$
\begin{aligned}
M= & \begin{array}{l}
f(\text { Pop, UnRat82, EmGr8082, Rato, Age82, Prof, YrEd82, } \\
\text { Race, YrsWk82, NumDep, SpWrk82, Home82, Prior })
\end{array} \\
D= & \begin{array}{l}
f(\text { Pop, UnRat82, EmGr8082, Rato, Age82, Prof, YrEd82, } \\
\text { Race, YrsWk82, NumDep, SpWrk82, Home82, Prior, }, \lambda)
\end{array}
\end{aligned}
$$

\section{The Data}

A sample of unemployed workers from the Panel Study of Income Dynamics (PSID) provided by the Institute for Social Research at the University of Michigan is used as the primary data source. Each year since 1968, the PSID has provided income, education, age, employment status, county of residence, and other demographic variables for more than 6,000 families located throughout the United States.

The PSID is one of the most widely used microdata sets in sociological and economic studies. For migration research, the use of PSID data provides three major advantages over the Public Use Samples generated from the decennial census. First, since yearly data are available, circular moves are detected that are unrecorded with U.S. Census data. Second, individual characteristics are known at the time of the move and do not have to be approximated with data from premigration or post-migration years. Third, with the use of the PSID, the researcher 
TABLE 1

Definition of Variables

\begin{tabular}{ll}
\hline \hline Variable Name & Definition \\
\hline M & $\begin{array}{l}\text { A binary variable equal to } 1 \text { if, between the } 1982 \text { and } \\
1983 \text { interview dates, the unemployed changed count } \\
\text { of residence; equal to } 0 \text { if otherwise.* }\end{array}$ \\
D & $\begin{array}{l}\text { Weeks spent unemployed during the worker's last } \\
\text { of unemployment in } 1982 .\end{array}$ \\
Pop & $\begin{array}{l}1980 \text { population per square mile in } 1982 \text { county of } \\
\text { residence. }\end{array}$
\end{tabular}

UnRat82

EmGr8082

1982 county unemployment rate in 1982 county of residence.

Rato

Age82

1980-82 rate of county employment growth in 1982 county of residence.

Prof

Proxy for replacement ratio. Logarithm of 1982 transfer income divided by 1981 wages.

Prof

Age of worker in 1982.

A binary variable equal to 1 if unemployed worker was formerly employed in a professional occupation; equal to 0 if otherwise.

YrEd82

Years of education as of 1982.

Race

YrsWk82 Unemployed's years of full-time work experience at the

Variable equal to 1 if worker is nonwhite; equal to 0 if white. time of the 1982 interview date.

NumDep Number of dependents in 1982.

SpWrk82

A binary variable equal to 1 if worker's spouse earned income in 1982; 0 if otherwise.

Home82

A binary variable equal to 1 if in 1982 worker owned the home in which he/she lived; equal to 0 if otherwise.

Prior

A binary variable equal to 1 if in 1982 worker was living in a state other than the one in which he/she grew up; equal to 0 if otherwise.

\footnotetext{
*Alternatively, migration was defined as an interstate change in residence. However, the results using interstate migration differed little from those obtained using intercounty moves. Those results are not presented, but may be obtained from the authors.
} 
can more accurately control for labor force status. For example, with the PSID, one can limit the sample so that it includes only heads-of-household who were in the labor force for the years of analysis. This restriction cannot be adequately enforced with U.S. Census data. ${ }^{7}$

The sample used in this study includes heads-of-household who were unemployed at some time in 1982 and were in the work force for both 1982 and 1983. Since a duration of joblessness variable was only available for unemployed workers, those who experienced no unemployment during the years 1982 and 1983 were excluded. Workers were not required to be employed in either year. They must, however, have been in the work force for all of 1982 and 1983. This period, which spans the 1982 recession, was chosen explicitly to increase the sample size. Data from the U.S. Bureau of the Census' County and City Data Book were used as the source for all place-specific variables. ${ }^{8}$

Sample statistics are presented in Table 2. Although mean search time for nonmovers exceeded that of movers, the difference between the two groups was not statistically significant. Thus, based upon simple univariate analysis of the data, one cannot reject either the Schwartz or Seater hypotheses. In order to disen-

TABLE 2

Sample Statistics

\begin{tabular}{|c|c|c|c|c|}
\hline Variable & ALL & & Nonmovers & Movers \\
\hline Number of observations & 864 & & 804 & 60 \\
\hline Duration of unemployment spell & 20.07 & & 20.27 & 17.38 \\
\hline Population per square mile & 1695.1 & & 1739.1 & 1105.3 \\
\hline Mean unemployment rate 1982 & $10.01 \%$ & & $9.98 \%$ & $10.47 \%$ \\
\hline Mean employment growth $1980-82$ & $-1.05 \%$ & & $-1.04 \%$ & $-1.22 \%$ \\
\hline Mean age & 33.2 & * & 33.6 & 26.6 \\
\hline$\%$ Professional & $5.2 \%$ & & $5.1 \%$ & $6.7 \%$ \\
\hline Mean years of education & 11.62 & & 11.58 & 12.10 \\
\hline \% White & $56.4 \%$ & * & $55.2 \%$ & $71.7 \%$ \\
\hline Mean years of work experience & 9.92 & * & 10.30 & 4.82 \\
\hline Median number of dependents & 1 & & 1 & 1 \\
\hline$\%$ with spouses who work & $46.5 \%$ & & $46.6 \%$ & $45.0 \%$ \\
\hline$\%$ Homeowners & $43.2 \%$ & $*$ & $45.6 \%$ & $10.0 \%$ \\
\hline$\%$ with prior migration & $25.3 \%$ & * & $24.3 \%$ & $40.0 \%$ \\
\hline
\end{tabular}

*Indicates that difference between movers and nonmovers is statistically significant at the 95 percent level of confidence. 
tangle interaction effects, the next section examines this issue in a multivariate framework.

\section{EMPIRICAL RESULTS}

Estimated coefficients of the migration equation, Equation (8), are obtained using binary probit regression and are presented in Table 3 (First Stage). From this estimation, $\lambda_{i}$ is retained and inserted in the estimation of Equation (9), the duration equation.

The results of empirically estimating Equation (9), using the functional form presented in Equation (7) and adjusting for selectivity bias, appear in Table 4, Column 2. Also listed in Table 4, Column 3 for comparison, is the estimation of the traditional job search model without adjusting for selectivity bias or controlling for migration. Data in Table 4 confirm the existence of selectivity bias, as measured by the statistically significant coefficient for $\lambda$.

TABLE 3

Binary Probit Estimates (First Stage)

\begin{tabular}{|c|c|c|c|}
\hline \multirow{2}{*}{$\begin{array}{l}\text { Variable Name } \\
\alpha\end{array}$} & & \multicolumn{2}{|c|}{ Coefficient (t-ratio) } \\
\hline & & -0.1471 & $(-0.185)$ \\
\hline Pop & $*$ & -0.1079 & $(-2.546)$ \\
\hline UnRat82 & & 0.0334 & (1.556) \\
\hline EmGr8082 & & -2.3811 & $(-1.273)$ \\
\hline Rato & & 0.0072 & $(0.515)$ \\
\hline Age82 & & -0.0339 & $(-1.403)$ \\
\hline Prof & & -0.1776 & $(-0.538)$ \\
\hline YrEd82 & & 0.0301 & (0.707) \\
\hline Race & $*$ & -0.4465 & $(-2.651)$ \\
\hline YrsWk82 & & -0.0162 & $(-0.553)$ \\
\hline NumDep & & -0.0632 & $(-0.867)$ \\
\hline SpWrk82 & & 0.1388 & $(0.876)$ \\
\hline Home82 & * & -0.9889 & $(-4.542)$ \\
\hline Prior & $*$ & 0.6038 & (3.579) \\
\hline \multicolumn{4}{|c|}{ *Indicates that coefficient is statistically significant at the 95 percent level of sigificance. } \\
\hline \multirow{4}{*}{$\begin{array}{l}\text { Log-likelihood (unrestricted) } \\
\text { Log-likelihood ( } \beta \text { 's }=0) \\
\chi^{2}(17) \\
\text { Significance level }\end{array}$} & & \multicolumn{2}{|c|}{-172.99} \\
\hline & & \multicolumn{2}{|c|}{-217.90} \\
\hline & & \multicolumn{2}{|c|}{8983} \\
\hline & & \multicolumn{2}{|c|}{$.32173 * 10^{-13}$} \\
\hline
\end{tabular}


Moreover, results from Table 4 indicate adjusting for selectivity bias produces several important and statistically significant impacts on the specification of the duration equation. First, results indicate that after correcting for selectivity bias, migration reduces search duration as measured by the negative estimated coefficient for $\boldsymbol{M}$. Assuming the labor market is composed of two subgroups, those who search outside the local labor market and move, and those who search only in the local labor market and do not move, empirical results indicate that the failure to control for the area of search produces heterogeneity in the estimated duration equation. When a sample is taken, a proportion $P$ will come from migrants and (1-P) from nonmigrants. According to the empirical results, as time passes, individuals in subgroup 1 (migrants) will complete their durations at a higher rate than subgroup 2 (nonmigrants). Thus, the fraction of total jobseekers from subgroup 1 declines. Since nonmigrants have a lower probability of obtaining a job, this shows up as a decline in the likelihood of obtaining a job over time. Thus, failure to control for migration produces heterogeneity, which results in

TABLE 4

Log-Likelihood Estimate of Unemployment Duration (Second Stage)

(1)

\begin{tabular}{lrrrrrr} 
Variable Name & \multicolumn{3}{c}{ Coefficient (t-ratio) } & \multicolumn{3}{c}{ Coefficient (t-ratio) } \\
\hline$\alpha$ & $*$ & 3.5210 & $(6.876)$ & $*$ & 2.5091 & $(5.409)$ \\
Pop & & 0.0423 & $(1.422)$ & $*$ & 0.0793 & $(2.752)$ \\
UnRat82 & $*$ & 0.0370 & $(2.367)$ & & 0.0191 & $(1.347)$ \\
EmGr8082 & & -1.4198 & $(-1.172)$ & & -0.7430 & $(-0.621)$ \\
Rato & $*$ & 0.0448 & $(4.717)$ & $*$ & 0.0411 & $(4.320)$ \\
Age82 & & 0.0047 & $(0.390)$ & & 0.0186 & $(1.548)$ \\
Prof & & -0.1864 & $(-0.900)$ & & -0.2421 & $(-1.136)$ \\
YrEd82 & & -0.0160 & $(-0.661)$ & & -0.0087 & $(-0.353)$ \\
Race & & 0.1328 & $(1.074)$ & $*$ & 0.3515 & $(3.034)$ \\
YrsWk82 & & -0.0180 & $(-1.370)$ & & -0.0201 & $(-1.506)$ \\
NumDep & & -0.0240 & $(-0.646)$ & & -0.0045 & $(-0.122)$ \\
SpWrk82 & 0.1011 & $(1.000)$ & & 0.0607 & $(0.602)$ \\
Home82 & $*$ & -0.5792 & $(-4.166)$ & $*$ & -0.2305 & $(-2.124)$ \\
Prior & & 0.2129 & $(1.758)$ & & -0.0091 & $(-0.083)$ \\
M & $*$ & -3.5499 & $(-4.329)$ & & & \\
$\lambda$ & $*$ & 1.8181 & $(4.147)$ & & & \\
Log-likelihood (unrestricted) & & -1382.3 & & & -1391.4 \\
Log-Likelihood ( $\beta$ 's =0) & & -1419.1 & & -1419.1 \\
\hline
\end{tabular}

*Indicates that estimated coefficient is statistically significant at the 95 percent level of confidence.
(2)

(3)

Selectivity Model

Traditional Model

$2.5091 \quad(5.409)$

$0.0793 \quad$ (2.752)

$0.0191 \quad(1.347)$

4.320)

$(1.548)$

$(-1.136)$

$(3.034)$

$(-1.506)$

-0.083) 
"over" estimates of unemployment duration and "under" estimates of the probability of obtaining a job for workers in the local labor market, ceteris paribus.

An estimate of the bias for movers is presented in Figure 1 where the cumulative density function is plotted for the altemative specifications. For clarity, the confidence intervals surrounding the estimates are suppressed. Ignoring considerations of confidence intervals, the selectivity model provides a higher estimated probability of reemployment over the duration range of 1 to 30 weeks of search in the sample. After 30 weeks of search, the cumulative probability of reemployment for the traditional model is estimated to be .422 , while for the selectivity model it is estimated to be .624 . Thus, according to these results, search models that do not control for migration selectivity greatly underestimate movers' probability of finding an acceptable job.

Furthermore, controlling for migration selectivity bias alters the estimated relationship between search duration and the variable Race, as it is now statistically insignificant, between search duration and the variable UnRat82 as it becomes statistically significant and between search duration and the variable Pop as it becomes statistically insignificant.

FIGURE 1

Cumulative Probability of Reemployment: Movers

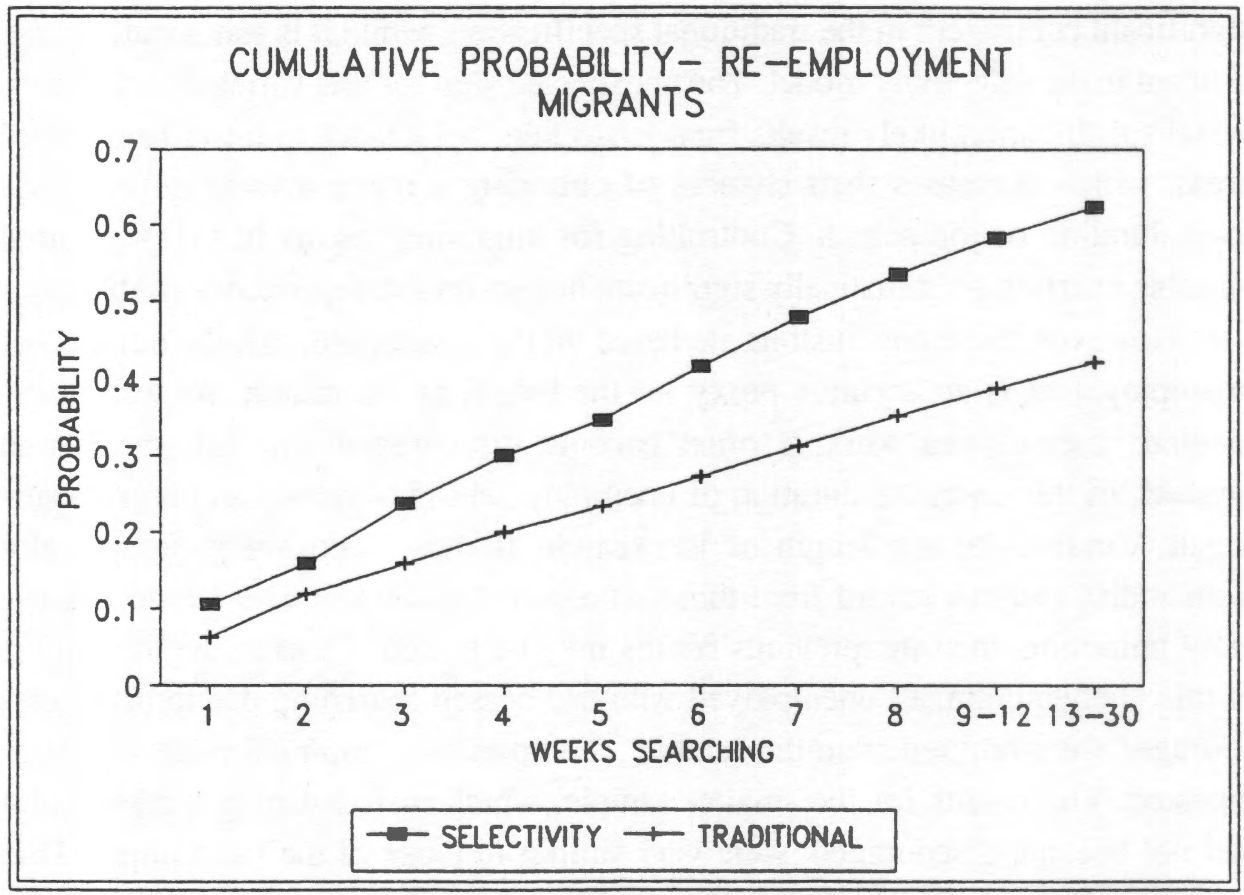


Past studies have found a consistent racial differential in unemployment duration (Wielgosz and Carpenter 1987; Bamett et al. 1989; Yoon 1981). In fact, Yoon $(1981,606)$ found that "... non-whites' mean search time for an offer is estimated to be approximately twice that of the white." None of the past studies examining racial differentials in search duration, however, control for migration. The results reported in Table 4 cast new light on the empirical finding of racial differentials and suggest that past studies, by failing to control for migration, have computed biased coefficients for race in duration equations. After adjusting for migration, race is found to have no statistically significant impact on the duration of unemployment. Rather, race's impact appears to be indirect. By being less geographically mobile, nonwhites incur a longer period of job search. Nonwhite's lower geographic mobility rates have been explained by their lack of job contacts and by their reluctance to leave family and friends. As a result, they tend to be less mobile and hence, experience an extended duration of unemployment.

The unemployment variable, UnRat82, becoming statistically significant is also of interest. Higher rates of unemployment in the home labor market reduce the probability of finding employment without moving and increase the net benefit of expanding the area of job search to geographically distant job markets. Thus, correcting for migration selectivity produces a coefficient for the unemployment rate variable more in conformity with expectations.

Finally, the variable Pop possesses an unexpected positive and statistically significant coefficient in the traditional specification, while it is statistically insignificant in the selectivity model. The unexpected sign for this variable in the traditional specification likely results from jobseekers' reluctance to move from metro areas, which decreases their chances of obtaining a job and likewise increases their duration of job search. Controlling for migration results in the population variable exerting no statistically significant impact on the dependent variable.

However, these conclusions are based on the assumption that the duration of unemployment is an accurate proxy for the length of job search. As well documented, unemployed workers often become discouraged and halt the search process. In this case, the duration of unemployment is often not an accurate surrogate variable for the length of job search. If those who are geographically mobile differ in this regard from those who search locally or who are geographically immobile, then the previous results may be biased. To examine the impact of this phenomenon, all unemployed who had ceased searching due to being discouraged were omitted from the sample. ${ }^{9}$ The previous empirical tests were then repeated. The results for the smaller sample, which included only workers who had not become discouraged, were very similar to those of the full sample. That is, the coefficient for the migration variable remained negative and statistically significant, and the coefficient for $\lambda$ remained positive and statistically significant. 
Additionally, the coefficient for Race remained statistically insignificant in the selectivity model.

The empirical findings of this study support the Schwartz model in which expanding the radius of search is hypothesized to reduce the duration of unemployment. Given the policy impact of a negative relationship between geographic mobility and duration of unemployment, these results are important and should generate more analyses of this phenomenon with larger data sets and with other time periods. Though research has considered the importance of migration of unemployed from areas with few available jobs to areas with greater job prospects, most policy has not incorporated an explicit recognition of the impact of geographic mobility on the length of unemployment. As such, the findings of this study confirm the importance of government programs that provide job and labor market information on distant labor markets to the unemployed. This information, according to the findings of this study, is expected to expand the unemployed's area of search and reduce his/her period of joblessness.

\section{CONCLUSION}

The results of this study suggest that not only must search models for the unemployed include a variable to account for migration, or the radius of search, but they must also recognize that both the probability of migration and the length of job search are simultaneously determined variables. When both of these recommendations are incorporated into a regression model, it produces a closer fit to the actual data and provides estimated coefficients that more accurately measure the impact of worker attributes upon the length of job search.

The findings of this study indicate that past studies, by failing to include a variable to account for migration of the unemployed, have misspecified the duration equation. By correcting for selectivity bias and migration, this study casts doubt on past findings that nonwhite unemployed workers, ceteris paribus, take longer to find an acceptable job. Past studies have called for corrective labor market policies for nonwhites to reduce their longer unemployment duration. Findings from this study indicate that the policy should be directed to nonwhites' lack of geographic mobility.

\section{ENDNOTES}

1. Also see Yoon (1981) for another example in which search intensity is assumed to vary. 
2. Furthermore, as proposed by an anonymous referee, search outside the local job area requires the jobseeker to invest more time obtaining job information, suggesting a positive link between migration and search duration.

3. Seater's model explicitly considers only the radius of search and the length of search.

4. Studies by Goss and Schoening (1985) and Harkman (1989) are exceptions.

5. Lancaster (1979) estimates the severity of the bias due to the omission of relevant variables in duration models. According to Lancaster, heterogeneity in duration models leads to misleading inferences about duration dependence and potentially misleading inferences regarding included explanatory variables.

6. David (1974) was the first to recognize that optimizing jobseekers simultaneously make their migration decision and the decision of how long or intensely to search. It is hypothesized that exogenous factors directly affect each endogenous factor. Likewise, factors such as home ownership would be expected to affect the unemployed worker's reservation wage and search time. Moreover, past research has concluded that prior geographic mobility reduces the variance in the distribution of the reservation wage and affects search time (Goss 1988).

7. Isserman et al. (1982) summarize and critique various sources of U.S internal migration data.

8. All county data came from the County \& City Data Book, U.S. Bureau of the Census, 1982.

9. The respondent was asked whether he/she had become discouraged during unemployment and quit searching.

\section{REFERENCES}

Bamett, A. H. , S. B. Caudill, and J. D. Jackson. "Job Search Duration and Marginal Tax Rates: An Empirical Inquiry." Southern Economic Journal (1989): 478-489.

Barnow, B., G. Cain, and A. Goldberger. "Issues in the Analysis of Selection Bias." University of Wisconsin, Department of Economics, 1981.

David, P. A. "Fortune, Risks, and the Micro-Economics of Migration." In Nations and Households in Economic Growth, edited by P. A. David and M. W. Reder. New York: Academic Press, 1974.

Ehrenberg, X., and R. L. Oaxaca. "Unemployment Insurance, Duration of Unemployment, and Subsequent Wage Gain. "American Economic Review 66 (1976): 754-766.

Feldstein, M. "Unemployment Policy after the Recession." Discussion paper no. 441, Harvard University, Cambridge, Massachusetts, 1975. 
Folmer, H., and J. Van Dijk. "Differences in Unemployment Duration: A Regional or a Personal Problem." Applied Economics (UK) 20, no. 9 (1988): 1233-1251.

"Differences in Characteristics Between Unemployed with Different Spells of Unemployment." Paper presented at Southern Regional Science Association Meeting, Washington, D.C., May 1985.

Goss, E. "Prior Geographic Mobility and Job Search Length." The Review of Regional Studies 18 (1988): 49-54.

Goss, E., and C. Paul. "The Impact of Unemployment Insurance Benefits on the Probability of Migration of the Unemployed." Journal of Regional Science 30, no. 3 (1990): 349-358.

Goss, E., and N. Schoening. "Search Time, Unemployment, and the Migration

Decision." Journal of Human Resources 19 (1985): 570-579.

Greene, W. Limdep. New York, 1985.

Harkman, A. "Migration Behavior Among the Unemployed and the Role of Unemployment Benefits." Papers of the Regional Science Association 66 (1989): 143-150.

Heckman, J. "Sample Selection Bias as a Specification Error." Econometrica (January 1979).

Holzer, Harry J. "Job Search by Employed and Unemployed Youth." Industrial and Labor Relations Review 40, no. 4 (July 1987): 601-611.

Isserman, Andrew, D. A. Plane, and D. B. McMillan. "Internal Migration in the United States: An Evaluation of Federal Data." Review of Public Data Use 10 (1982): 73-82.

Kooreman, P., and G. Ridder. "The Effects of Age and Unemployment Percentage on the Duration of Unemployment." European Economic Review 20 (1982): 45-57.

Lancaster, Tony. "Econometric Methods for the Duration of Unemployment." Econometrica 47, no. 4 (1979): 939-956.

Marston, S. "The Impact of Unemployment Insurance on Job Search." Brookings Papers on Economic Activity (1975): 13-60.

Mortensen, D. "A Theory of Wage and Employment Dynamics." In Microeconomic Foundations of Employment and Inflation Theory, edited by Edmund S. Phelps. New York, 1970.

Nickell, S. "Estimation of the Probability of Leaving Unemployment" Econometrica 47, no. 5 (1979): 1249-1264.

Schwartz, A. "Migration, Age, and Education." Journal of Political Economy 84 (1976): 701-19.

Seater, John J. "Job Search and Vacancy Contracts." American Economic Review 69, no. 3 (1979): 411-419. 
Wielgosz, John B., and Susan Carpenter. "The Effectiveness of Alternative Methods of Searching for Jobs and Finding Them." American Journal of Economics and Sociology 46, no. 2 (April 1987): 151-165.

Yoon, Bong Joon. "A Model of Unemployment Duration with Variable Search Intensity." The Review of Economics and Statistics 63, no. 4 (November 1981): 599-609. 